\title{
Combinatorial molecule screening identified a novel diterpene and the BET inhibitor CPI-203 as differentiation inducers of primary acute myeloid leukemia cells
}

Haematologica 2021

Volume 106(10):2566-2577

\section{Correspondence:}

MATTIAS MAGNUSSON

mattias.magnusson@med.lu.se

Received: February 17, 2020.

Accepted: August 25, 2020.

Pre-published: August 27, 2020.

https://doi.org/10.3324/haematol.2020.249177

(C)2021 Ferrata Storti Foundation

Material published in Haematologica is covered by copyright. All rights are reserved to the Ferrata Storti Foundation. Use of published material is allowed under the following terms and conditions:

https://creativecommons.org/licenses/by-nc/4.0/legalcode. Copies of published material are allowed for personal or internal use. Sharing published material for non-commercial purposes is subject to the following conditions:

https://creativecommons.org/licenses/by-nc/4.0/legalcode, sect. 3. Reproducing and sharing published material for commercial purposes is not allowed without permission in writing from the publisher.
Simon Hultmark, ${ }^{1}$ Aurélie Baudet, ${ }^{1,2}$ Ludwig Schmiderer, ${ }^{1}$ Pavan Prabhala ${ }^{1}$ Sara Palma-Tortosa, ${ }^{3}$ Carl Sandén, ${ }^{4}$ Thoas Fioretos, ${ }^{4}$ Rajkumar Sasidharan, ${ }^{5}$ Christer Larsson, ${ }^{6}$ Sören Lehmann, ${ }^{7,8}$ Gunnar Juliusson, ${ }^{2,9}$ Fredrik Ek ${ }^{10 \#}$ and Mattias Magnusson ${ }^{1 \#}$

${ }^{1}$ Division of Molecular Medicine and Gene Therapy, Lund Stem Cell Center, Lund University, Lund, Sweden; 'Division of Molecular Hematology, Lund Stem Cell Center, Lund University, Lund, Sweden; ' 2 Laboratory of Stem Cells and Restorative Neurology, Lund Stem Cell Center, Lund University, Lund, Sweden; ${ }^{4}$ Division of Clinical Genetics, Department of Laboratory Medicine, Lund University, Lund, Sweden; ${ }^{5}$ Solvuu, Inc., New York, NY, USA; ${ }^{6}$ Division of Translational Cancer Research, Lund University, Lund, Sweden; ${ }^{7}$ Department of Medical Sciences, Uppsala University Hospital, Uppsala, Sweden; ${ }^{8}$ Department of Medicine, Karolinska Institute, Stockholm, Sweden; ${ }^{9}$ Department of Hematology, Skane University Hospital, Lund, Sweden and ${ }^{10} \mathrm{Chemical}$ Biology \& Therapeutics, Lund University, Lund, Sweden.

"FE and MM contributed equally as co-senior authors.

\section{ABSTRACT}

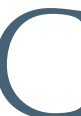

ombination treatment has proven effective for patients with acute promyelocytic leukemia, exemplifying the importance of therapy targeting multiple components of oncogenic regulation for a successful outcome. However, recent studies have shown that the mutational complexity of acute myeloid leukemia (AML) precludes the translation of molecular targeting into clinical success. Here, as a complement to genetic profiling, we used unbiased, combinatorial in vitro drug screening to identify pathways that drive AML and to develop personalized combinatorial treatments. First, we screened 513 natural compounds on primary AML cells and identified a novel diterpene (H4) that preferentially induced differentiation of FLT3 wild-type AML, while FLT3-ITD/mutations conferred resistance. The samples responding to $\mathrm{H} 4$, displayed increased expression of myeloid markers, a clear decrease in the nuclear-cytoplasmic ratio and the potential of re-activation of the monocytic transcriptional program reducing leukemia propagation in vivo. By combinatorial screening using $\mathrm{H} 4$ and molecules with defined targets, we demonstrated that $\mathrm{H} 4$ induces differentiation by the activation of the protein kinase $\mathrm{C}(\mathrm{PKC})$ signaling pathway, and in line with this, activates PKC phosphorylation and translocation of PKC to the cell membrane. Furthermore, the combinatorial screening identified a bromo- and extra-terminal domain (BET) inhibitor that could further improve H4-dependent leukemic differentiation in FLT3 wild-type monocytic AML. These findings illustrate the value of an unbiased, multiplex screening platform for developing combinatorial therapeutic approaches for AML.

\section{Introduction}

Acute myeloid leukemia (AML) is the most common form of adult acute leukemia. It is characterized by the accumulation of immature myeloid cells with increased self-renewal, apoptotic resistance and dysfunctional differentiation leading to subsequent infections, anemia and bleeding. ${ }^{1}$ Although the majority of patients initially respond to the standard of care (cytotoxic chemotherapy), a substantial number of patients will relapse with a 10 -year survival of only $20 \%$ 
above 60 years of age. ${ }^{2}$ The overall poor survival highlights a dire need for better therapies.

During the past years, several targeted therapies have been developed, designed to uniquely target disease-specific molecular events, such as mutant isocitrate dehydrogenase proteins, ${ }^{3,4} \mathrm{BCR} / \mathrm{ABL}^{5}$ and PML/RARA $\alpha$ fusion proteins $^{6}$ as well as FLT3-ITD mutations. ${ }^{7}$ Targeted therapies hold the promise of being superior to standard chemotherapy with increased specificity, improved efficiency, and reduced toxicity/side-effects. ${ }^{8}$ However, single-agent targeted therapies have had only moderate clinical success. For instance, targeting mutant IDH2 or FLT3-ITD AML with specific inhibitors produced initial molecular responses, but these promising early results were frequently followed by treatment resistance and relapse. ${ }^{3,9,10}$ Relapse and resistance could be explained by the expansion of malignant clones that were not dependent on the targeted mutation, ${ }^{11,12}$ indicating that singleagent targeted therapy would not be sufficient for leukemia clearance.

In line with this, combining arsenic salt with standard all-trans retinoic acid therapy for acute promyelocytic leukemia enabled simultaneous activation of both RAR $\alpha$-dependent granulocytic differentiation and the PML-dependent apoptosis/senescence pathways. ${ }^{13-15}$ This simultaneous targeting of multiple drivers is now the standard treatment for patients carrying PML-RAR $\alpha$ rearrangements and results in disease clearance in more than $90 \%$ of these patients who previously had poor prognoses. ${ }^{6}$ This demonstrated the need for tailored treatment targeting multiple mechanisms driving the disease. However, next-generation sequencing has shown that most cases of AML have a far more complex mutational landscape with an average of 13 mutations per sample (excluding alterations in noncoding regions) ${ }^{16}$ as well as complex karyotypes, highlighting the challenge of translating multiple-targeted therapy into clinical success for the treatment of AML.

As a complement to genetic profiling, unbiased in vitro drug screening can be used to reveal pathways that drive disease and identify novel therapeutic targets. By combining drug screening and the multiplex power of flow cytometry, we were also previously able to simultaneously identify compounds with cytotoxicity and differentiation-inducing potential, defining a paradigm for high throughput delineation of potential combination therapies. ${ }^{17}$ Furthermore, unlike xenograft models, a short culture ( $<1$ week) can efficiently maintain the polyclonality of AML, making in vitro models and high throughput drug screening a powerful tool for developing personalized therapies for AML. ${ }^{18,19}$

Here, to identify patient-specific combinatorial treatment options, we improved our stroma co-culture model for mechanistic and combinatorial screening of primary AML cells. ${ }^{17}$ We identified $\mathrm{H} 4$, a novel, natural compound that induced differentiation of FLT3 wild-type primary AML samples, while FLT3-ITD/mutated AML were found to be resistant to $\mathrm{H} 4$ treatment. Using combinatorial screening, we established that $\mathrm{H} 4$ induced differentiation by activation of protein kinase $\mathrm{C}$ (PKC) signaling and that, for FLT3 wild-type monocytic AML samples, the effect of $\mathrm{H} 4$ was further enhanced by a bromoand extra-terminal domain (BET) inhibitor, demonstrating the potential of unbiased approaches in the development of personalized treatments.

\section{Methods}

The methods are described in detail in the Online Supplementary Material.

\section{Collection of healthy bone marrow, umbilical cord blood, and acute myeloid leukemia samples}

Samples were collected in Swedish hospitals, in accordance with the Declaration of Helsinki and with the approval of the local ethical committees (dnr 2014/596, 826/2004 and 2010/1893-31/2) Mononuclear cells from umbilical cord blood and healthy bone marrow were enriched for $\mathrm{CD} 34^{+}$cells and primary AML samples for mononuclear cells before freezing. The characteristics of the patients' samples are presented in Table 1 and Online Supplementary Table S1.

\section{Small molecule libraries}

The natural product library was obtained from AnalytiCon Discovery (Potsdam, Germany), as a $10 \mathrm{mM}$ stock solution in dimethylsulfoxide (DMSO). H4 product \#NP-000694. The anticancer drug library was obtained from Selleckchem (L3000).

\section{Small molecule screening}

Small molecule screening has been previously described. ${ }^{17}$ Briefly, primary hematopoietic cells were plated on irradiated OP9M2 stromal cells in medium supplemented with human cytokines (stem cell factor, thrombopoietin, FLT3, interleukin 6, and interleukin 3). After 36 to $48 \mathrm{~h}$, compounds were added at the final concentration of $0.5 \mu \mathrm{M}$ and $10 \mu \mathrm{M}$. AML cell lines were treated for 3 days and primary AML samples for 4 days before analysis.

\section{Flow cytometry analysis}

Cultured cells were transferred to 96-well round-bottomed plates, washed, and then stained with anti-human monoclonal antibodies (CD11b, CD15, CD64). Cells were analyzed using a FACSCanto II analyzer with a high-throughput unit (Becton Dickinson).

\section{Long-term culture}

Every 4 days, the medium was changed completely by adding new medium containing $\mathrm{H} 410 \mu \mathrm{M}$ or DMSO. Cells were immunophenotyped and a volumetric cell count performed using flow cytometry.

\section{Cell cycle inhibition}

AML-3 cells were pre-treated for 5 days with palbociclib $5 \mu \mathrm{M}$ or DMSO before $\mathrm{H} 4$ was added with a complete change of medium. On days 5 and 9 , cells were anlyzed by immunostaining, volumetric cell count, and cell cycle status using DAPI and PE Mouse AntiKi-67 Set (BioLegend).

\section{In vitro treatment, transplantation into NRGS mice and analysis of engraftment}

Cultured cells from an equal number of wells per treatment group were transplanted into pre-conditioned (600 cGy radiation) NRGS mice. When mice from the DMSO group showed signs of sickness, mice from both groups were sacrificed. Spleen and bone morrow were collected, stained for human CD45 and CD33 (BioLegend) and analyzed by flow cytometry.

\section{Protein kinase $\mathbf{C}$ translocation assay}

HEK-293 cells were transfected with plasmids encoding EGFPtagged full-length $\mathrm{PKC}^{20}$ and treated with $40 \mu \mathrm{M}$ of $\mathrm{H} 4$. Translocation of PKC-EGFP from the cytoplasm to the plasma membrane was measured using live imaging on a Zeiss 780 confocal laser scanning microscope. 
Table 1. Primary acute myeloid leukemia samples and their response to $\mathrm{H} 4$.

\begin{tabular}{|c|c|c|c|c|c|c|c|c|c|}
\hline Sample & Sulbtype & Relapse & Karyotype & FLT3 & Additional mutations & $\begin{array}{l}\text { D11b or } \\
\text { DMSO }\end{array}$ & $\begin{array}{l}\text { 11b and CD1 } \\
\text { H4 } 10 \mu \mathrm{M}\end{array}$ & $\begin{array}{l}\text { Cell \#/ } \\
\text { DMSO }\end{array}$ & $\begin{array}{c}\text { MFI FSC-A } \\
\text { \& SSC-A/ } \\
\text { DMSO }\end{array}$ \\
\hline AML-1 & M4 & Yes & Normal & ITD & DNMT3A, NPM1 & $23.2 \% *$ & $23.8 \% *$ & 1.39 & $1.02 / 0.98$ \\
\hline AML-2 & M2 & No & Normal & WT & NPM1, TET2 & $31.4 \% *$ & $47.4 \% *$ & 0.88 & $0.95 / 1.00$ \\
\hline AML-3 & M5 & Yes & Complex & WT & TP53 & $20.8 \%$ & $62.9 \%$ & 0.73 & $1.09 / 1.27$ \\
\hline AML-4 & M1 & No & Normal & ITD & DNMT3A, NPM1 & $14.6 \% *$ & $19.0 \% *$ & 1.02 & $0.89 / 0.78$ \\
\hline AML-5 & M0 & No & Normal & WT & DNMT3A, IDH1, NOTCH1, SRSF2 & $14.8 \% *$ & $7.6 \% *$ & 0.62 & $0.82 / 0.89$ \\
\hline AML-6 & Unspecified & No & Complex & WT & TP53, RUNX1, NRAS & $65.2 \%$ & $73.1 \%$ & 0.04 & $0, .86 / 1.15$ \\
\hline AML-7 & Unspecified & No & Complex & WT & NPM1, IDH2, RUNX1, PHF6 & $28.3 \% *$ & $57.7 \% *$ & 0.64 & $0.91 / 0.77$ \\
\hline AML-8 & M5 & No & Normal & ITD & DNMT3A, NPM1, SMC3, PTEN & $23.1 \%$ & $34.9 \%$ & 1.18 & $1.02 / 1.01$ \\
\hline AML-9 & M5 & NK & NK & WT & $\mathrm{NI}$ & $15.9 \% *$ & $45.0 \% *$ & 0.73 & $0.97 / 1.05$ \\
\hline AML-10 & M5 & NK & Normal & Mut & DNMT3A, NPM1, TET2 & $28.8 \%$ & $29.6 \%$ & 0.69 & $0.96 / 0.90$ \\
\hline AML-11 & M5 & No & NK & Mut & CEBPA & $25.4 \%$ & $35.2 \%$ & 0.49 & $0.98 / 1.30$ \\
\hline AML-12 (PDX) & M4 & No & Normal & WT & NPM1, DNMT3A, IDH2 & $64.3 \%$ & $75.5 \%$ & 0.82 & $0.97 / 0.98$ \\
\hline AML-13 & M1 & NK & Normal & WT & NI & $22.3 \%$ & $25.0 \%$ & 1.09 & $1.02 / 1.00$ \\
\hline AML-14 & M1 & NK & Complex & WT & DNMT3A & $38.8 \%$ & $64.4 \%$ & 0.22 & $0.93 / 1.06$ \\
\hline AML-15 & M3 & NK & Normal & Mut & NPM1, CEBPA, PML-RARA & $21.5 \%$ & $29.3 \%$ & 1.03 & $1.01 / 1.11$ \\
\hline AML-16 & M0 & Yes & Normal & WT & TP53, DNMT3A, STAG2 & $69.8 \%$ & $72.4 \%$ & 0.66 & $0.97 / 1.03$ \\
\hline AML-17 & NOS & NK & Normal & ITD & TET2, KRAS, WT1 & $78.5 \%$ & $78.3 \%$ & 0.13 & $0.80 / 0.81$ \\
\hline AML-18 & MD & NK & Normal & WT & NPM1, CEBPA & $76.3 \%$ & $86.9 \%$ & 0.25 & $0.93 / 0.88$ \\
\hline AML-19 & M2 & NK & Normal & ITD & $\mathrm{NI}$ & $44.8 \%$ & $47.6 \%$ & 0.48 & $1.00 / 0.94$ \\
\hline AML-20 & M1 & No & NK & ITD & $\mathrm{NI}$ & $64.5 \% *$ & $72.5 \% *$ & 0.94 & $0.91 / 0.94$ \\
\hline $\begin{array}{l}\text { Ctrl UCB } \\
\text { (MNC) }\end{array}$ & NA & NA & NA & NA & NA & $11.6 \%$ & $18.0 \%$ & 1.06 & $1.03 / 1.09$ \\
\hline $\begin{array}{l}\text { Ctrl UCB } \\
\quad\left(\mathrm{CD} 34^{+} \mathrm{MNC}\right)\end{array}$ & $\mathrm{NA}$ & NA & NA & NA & NA & $12.7 \%$ & $18.3 \%$ & 0.32 & $1.01 / 0.99$ \\
\hline $\begin{array}{l}\text { Ctrl BM } \\
\quad\left(\mathrm{CD} 34^{+} \mathrm{MNC}\right)\end{array}$ & $\mathrm{NA}$ & NA & NA & NA & NA & $32.5 \%$ & $24.9 \%$ & 1.18 & $1.98 / 0.99$ \\
\hline
\end{tabular}

AML: acute myeloid leukemia; DMSO: dimethylsulfoxide; MFI: mean fluorescent intensity; SSC: side scatter; FSC: forward scatter; ITD: internal tandem duplication; WT: wild-type; Mut: mutated; NK: not known; NI: not identified; NA: not applicable; PDX: patient-derived xenograft; Ctrl: healthy control; UCB: umbilical cord blood; MNC: mononuclear cells; BM: bone marrow.

\section{Immunostaining of protein kinase $\mathbf{C}$ phosphorylation}

Cells were treated for 30 min with $\mathrm{H} 410 \mu \mathrm{M}$ or $40 \mu \mathrm{M}$ and then cytospun onto polysine adhesion slides and stained with primary anti-PKC $\alpha$ phospho S657 + Y658 and anti-PKC $\varepsilon$ phospho S729 (Abcam) antibodies for $1 \mathrm{~h}$ at room temperature followed by secondary anti-rabbit antibody (Abcam). Nuclei were stained with Hoechst for $5 \mathrm{~min}$ and sections mounted with Dabco mounting medium. Confocal images were taken with a maximum intensity projection of $5 \mu \mathrm{m}$ using a $63 \mathrm{X}$ objective (LSM780, Zeiss, Germany).

\section{Results}

\section{Small natural product screening identified compounds with toxic or myeloid differentiation potential on acute myeloid leukemia cells}

To identify novel targets for combinatorial treatment, we performed a primary small molecule screen using 513 purified natural products selected for their structural diversity and the potential for further drug refinement. We screened three primary AML samples with different subtypes and genotypes (AML-1 to -3; Table 1 and Online Supplementary Table S1) as well as healthy bone marrow cells using our coculture platform (Figure 1A) ${ }^{17,21}$ The drug response was evaluated 4 days after treatment at two concentrations ( 0.5 $\mu \mathrm{M}$ and $10.0 \mu \mathrm{M})$ using flow cytometry and compared to control (DMSO-treated) AML cells as well as to healthy bone marrow cells. We identified 44 compounds with a biological effect which we divided into three categories: cytotoxic (reduction of volumetric cell count by at least $50 \%)$, cytotoxic and myeloid differentiation potential (increase in $\mathrm{CD} 11 \mathrm{~b}$ expression) or myeloid differentiation potential without cytotoxicity (Figure 1B, C and Online Supplementary Figure S1A). Within each category, we identified molecular groups with similar structures. Molecules that belonged to amaryllidaceae and indole alkaloids were mainly toxic, while rotenoids and cardiac glycosidases were mainly toxic and differentiating (Figure 1C). Finally, diterpenes mainly demonstrated the potential to induce differentiation of primary leukemic cells without being toxic to healthy bone marrow cells. This group was thus selected for further characterization as a potential therapeutic option with fewer side effects than chemotherapy (Figure 1C).

\section{H4 is a diterpene with the potential to differentiate pri- mary FLT3 wild-type acute myeloid leukemia cells}

Next, we selected the most potent diterpene, a novel jatrophane called $\mathrm{H} 4$, which was originally isolated from the plant Euphorbia paralias (Figure 2A). ${ }^{22}$ In the initial screen, $\mathrm{H} 4$ 
Primary AML or

healthy control on

OP9M2 stroma

( 2 days pre-culture)

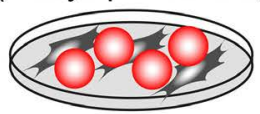

513 natural products
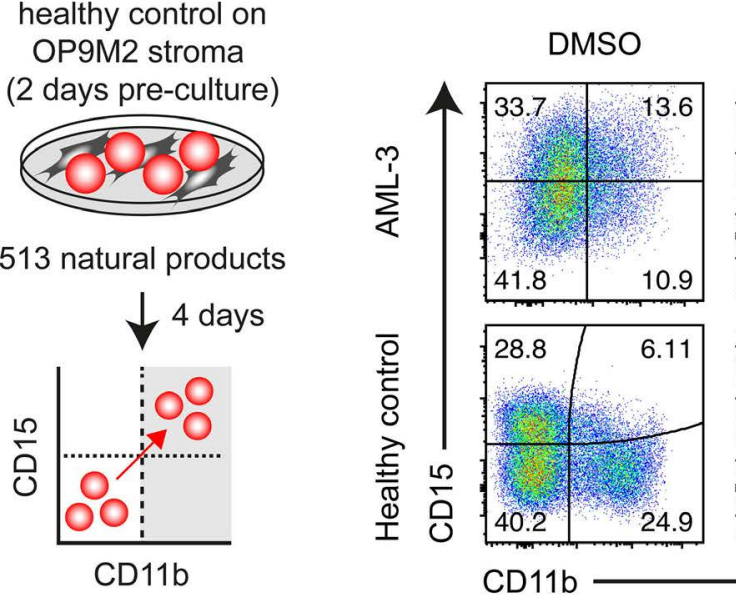

Hit compounds organized in categories:

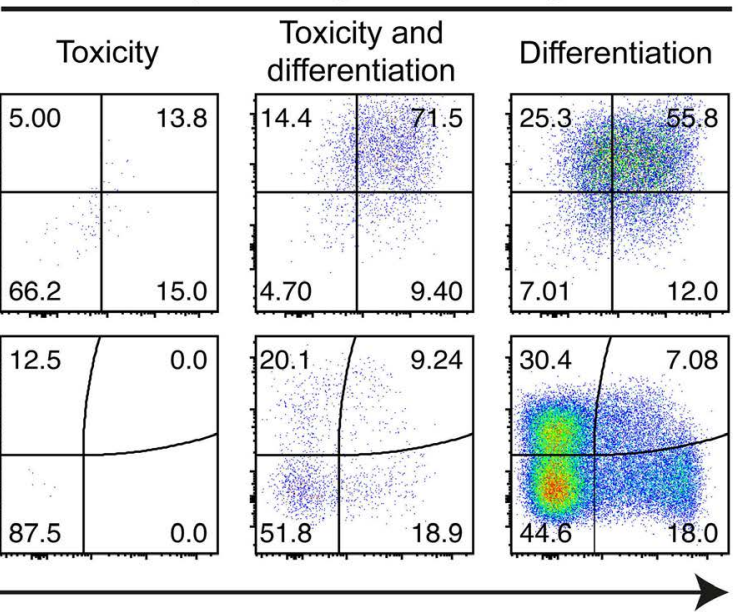

C

Toxicity

Toxicity and differentiation Differentiation

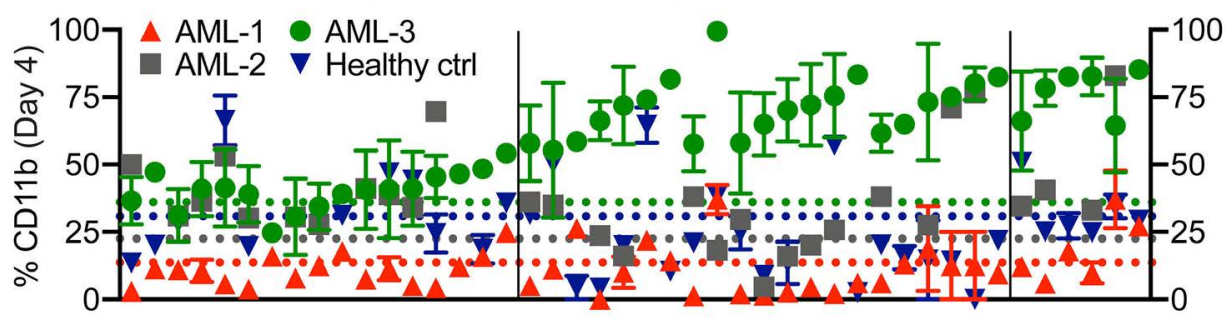

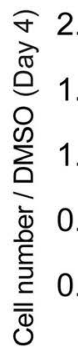

$0-1$
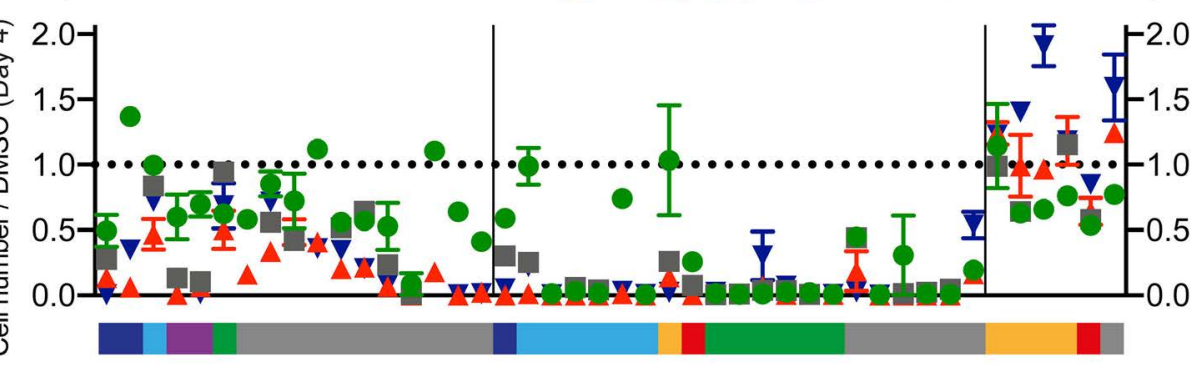

5

Rotenoids

Cardiac glycosides

Amaryllidaceae alkaloids

Indole

alkaloids

Hit compounds $(10 \mu \mathrm{M})$

Figure 1. Screening of small natural products identifies compounds that are toxic to acute myeloid leukemia cells or have myeloid differentiation potential. (A) Primary acute myeloid leukemia (AML) cells and control cells (CD34+ bone marrow cells) from healthy volunteers were cultured for 2 days on irradiated stromal cells and then treated with 513 natural product compounds at the concentrations of $10 \mu \mathrm{M}$ and $0.5 \mu \mathrm{M}$. Four days later, cells were collected and assayed by flow cytometry to measure their viability (volumetric cell count) and myeloid differentiation (CD11b and CD15 expression). (B) An illustrative example of a hit compound from each of the three categories: toxicity, toxicity and differentiation, and differentiation. (C) Hit compounds were categorized into biological response groups and then on molecular structure. In the 'differentiation' category: CD11b $>55 \%$ (AML-3) and cell number/DMSO ratio $>0.5$ (all samples). In the 'toxicity and differentiation' category: $\mathrm{CD} 11 \mathrm{~b}>55 \%$ (AML-3) and cell number/DMSO ratio $<0.5$ (any sample). In the 'toxicity' category: CD11b $<55 \%$ (AML-3) and cell number/DMSO ratio <0.5 (any samples). The baseline expression of $\mathrm{CD} 11 \mathrm{~b}$ for each sample is indicated with a dotted line in a designated color. Data are shown as mean \pm standard error of mean from independent experiments, healthy control $n=2, A M L-1 n=2-3, A M L-2 n=1, A M L-3 n=2-3$. DMSO: dimethylsulfoxide, Ctrl: control.

was specifically efficient in differentiating the AML-3 sample, which was isolated from a patient with chemotherapyresistant AML (Table 1 and Online Supplementary Figure $S 1 B)$. A dose-response experiment demonstrated that 10 $\mu \mathrm{M}$ was the optimal concentration to induce myeloid differentiation (CD11b+ cells: DMSO, 20\%, H4, 65\%) with May-Grünwald Giemsa staining showing an apparent reduction in nuclear to cytoplasmic ratio, supporting the induction of myeloid differentiation (Figure 2B). The relative decrease to DMSO in cell number at the $10 \mu \mathrm{M}$ concentration on day 4 was not due to increased apoptosis or necrosis throughout the 4-day culture (Figure 2C). In line with this, absolute cell count during long-term culture (4 weeks) of AML-3 together with H4 demonstrated an initial- ly increased proliferation of the treated cells followed by a sharp decline in cell number after 8 days in culture, while the control cells exposed to DMSO continued to expand (Figure 2D). In addition, the proportion of $\mathrm{CD}_{11 b^{+}}$cells increased with continuous treatment with $\mathrm{H} 4$, further supporting that $\mathrm{H} 4$ induces differentiation of AML cells (Online Supplementary Figure S2A). However, since leukemia-propagating cells (leukemia stem cells) are known to be quiescent and thought to be resistant to chemotherapy, we next assessed the potential of $\mathrm{H} 4$ to induce differentiation of non-cycling cells, $\mathrm{G}_{0}$-arrested cells, by pre-treating AML-3 cells with the cell cycle inhibitor palbociclib ${ }^{23}$ for 5 days (Online Supplementary Figure S2B). Even with the continuous addition of palbociclib together with $\mathrm{H} 4$, the upregulation 
A

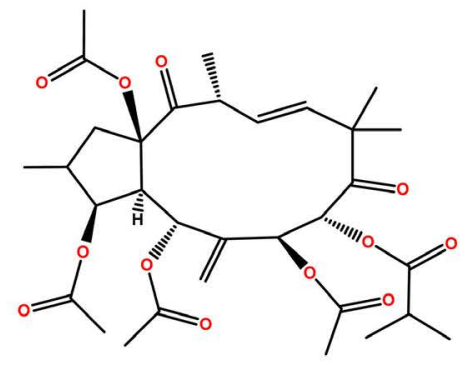

Compound $\mathrm{H} 4$
B

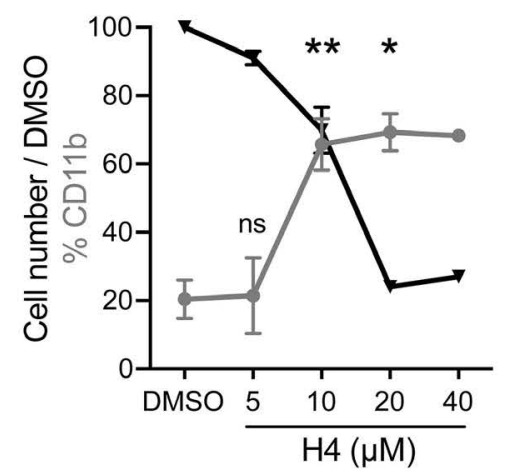

Differentiation in AML-3 (Day 4)

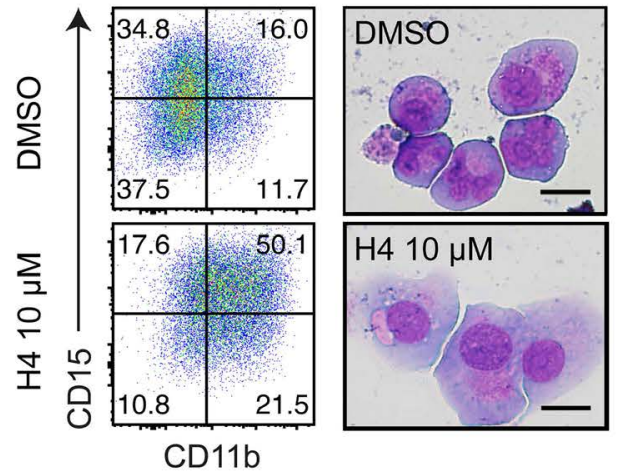

C

\section{Apoptosis and necrosis (AML-3)}

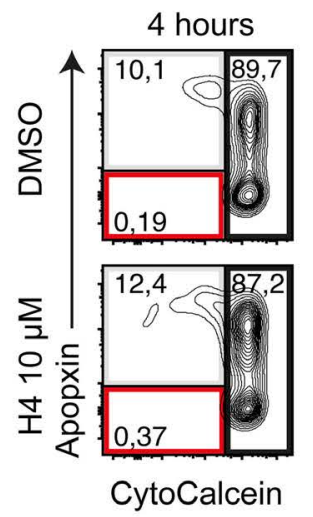

$\mathbf{F}$

Engraftment of in vitro treated AML-3

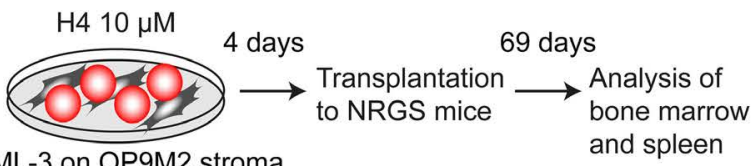

AML-3 on OP9M2 stroma

(pre-cultured for 2 days)

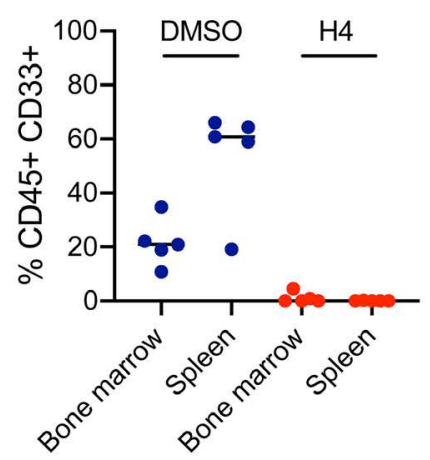

D

\section{Long-term culture}

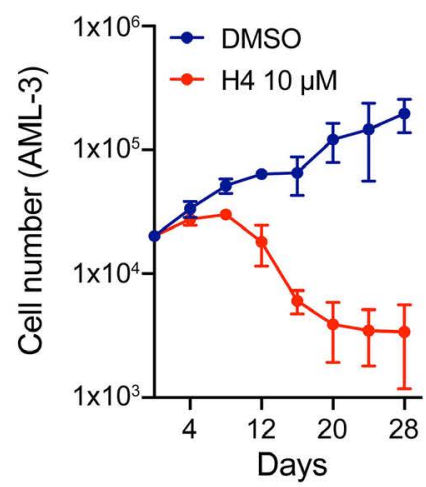

E

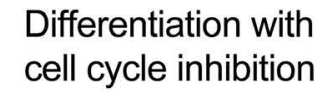

Differentiation with
cell cycle inhibition

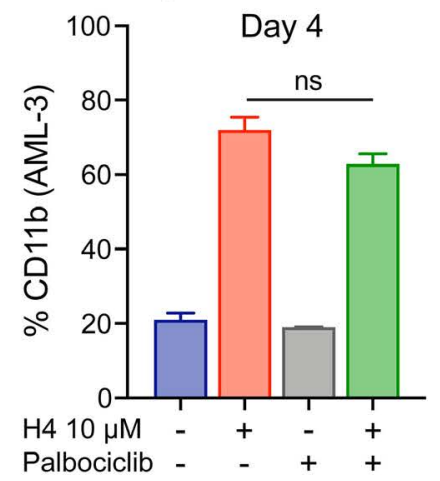

G

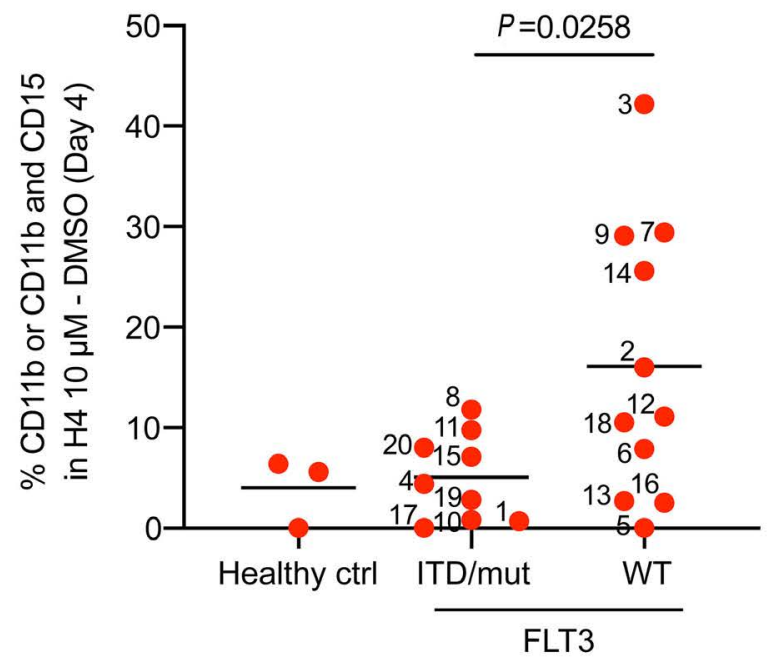

Figure 2. H4 is a jatrophane with differentiation potential for primary FLT3 wild-type acute myeloid leukemia cells. (A) Molecular structure of the natural compound H4. (B) The optimal concentration of $\mathrm{H} 4$ was $10 \mu \mathrm{M}$ for primary AML-3 cells. The data are shown as mean \pm standard error of mean from independent experiments, DMSO ( $n=5), \mathrm{H} 45 \mu \mathrm{M}(\mathrm{n}=2), \mathrm{H} 410 \mu \mathrm{M}(\mathrm{n}=6), \mathrm{H} 420 \mu \mathrm{M}(\mathrm{n}=2), \mathrm{H} 440 \mu \mathrm{M}(\mathrm{n}=1)(* * P<0.01, * P<0.05$, ns not significant, using one-way analysis of variance). On the right, representative change in cell morphology and myeloid differentiation markers after treatment with $\mathrm{H} 410 \mu \mathrm{M}$. Scale bars represent $10 \mu \mathrm{m}$. (C) No detected increase in the percentage of viable, apoptotic and necrotic AML-3 cells after treatment with $\mathrm{H} 4 \mu \mathrm{M}$. The data are shown as mean \pm standard deviation (SD) of technical replicates. (D) Long-term culture of AML-3 cells on OP9M2 stroma cells. The data are shown as mean \pm SD of technical replicates. (E) H4 induced differentiation of AML-3 cells that had been pretreated for 5 days with the CDK4/6 cell cycle inhibitor palbociclib, after 4-day combination treatment with the CDK4/6 cell cycle inhibitor palbociclib $5 \mu \mathrm{M}$. The data are shown as mean \pm SD of technical replicates. (ns not significant, using an unpaired two-tailed $t$-test). ( $F$ ) Engraftment levels of in vitro treated human AML3 cells transplanted into mice. (G) H4 triggered the strongest differentiation response in FLT3 wild-type acute myeloid leukemia samples. The data are shown with the average response from each sample labeled with their respective sample number for easier identification. (significance test using an unpaired two-tailed $t$-test with the Welch correction). DMSO: dimethylsulfoxide; AML: acute myeloid leukemia; Ctrl: control; ITD: internal tandem duplication; mut: mutated. 
of CD11b expression was similar to that with $\mathrm{H} 4$ alone, suggesting that quiescent cells can also be differentiated by $\mathrm{H} 4$ (Figure 2E). Finally, to further evaluate the effect on leukemia stem cell function, AML-3 cells were treated for 4 days in vitro and transplanted into irradiated NRGS mice (DMSO control, 34,200 cells per mouse vs. H4-treated, 18,800 cells per mouse, $97 \%$ viability in both groups). Ten weeks after transplantation, the control mice had to be

$\mathrm{H} 4$ upregulated genes in red and downregulated genes in blue

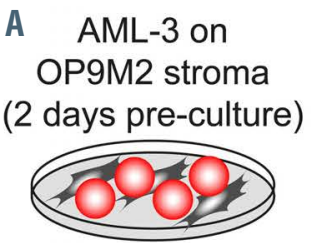

$\mathrm{H} 4$ $\downarrow 16$ hours

Cell sorting Microarray

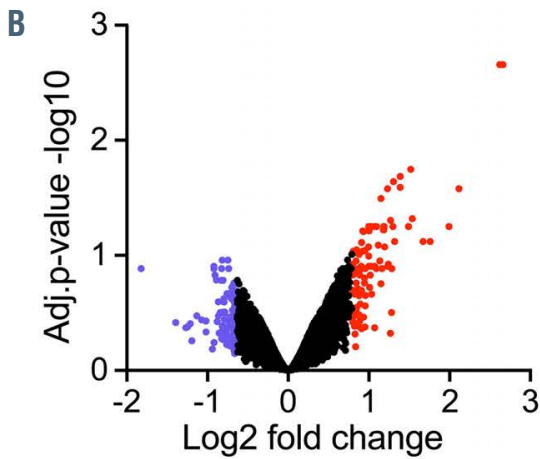

$\mathrm{H} 4$ induced states and processes

\begin{tabular}{lcc}
\hline Hallmark GSEA & NES & FDR q-val \\
\hline MYC TARGETS V2 & 2.46 & $<0.0001$ \\
INTERFERON ALPHA RESPONSE & 2.18 & $<0.0001$ \\
TNFA SIGNALING VIA NFKB & 1.98 & $<0.0001$ \\
OXIDATIVE PHOSPHORYLATION & 1.98 & $<0.0001$ \\
IL2 STAT5 SIGNALING & 1.91 & $<0.0001$ \\
MYC TARGETS V1 & 1.86 & $<0.0001$ \\
INTERFERON GAMMA RESPONSE & 1.82 & 0.0003 \\
UNFOLDED PROTEIN RESPONSE & 1.80 & 0.0009 \\
INFLAMMATORY RESPONSE & 1.59 & 0.0142 \\
UV RESPONSE UP & 1.58 & 0.0165 \\
REACTIVE OXIGEN SPECIES PATHWAY & 1.54 & 0.0220 \\
\hline
\end{tabular}

$\mathrm{F}$

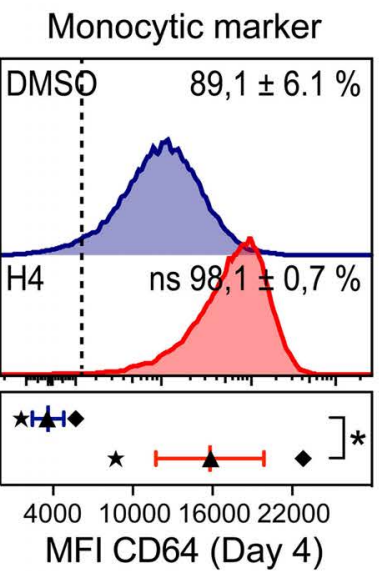

G

Protein synthesis rate

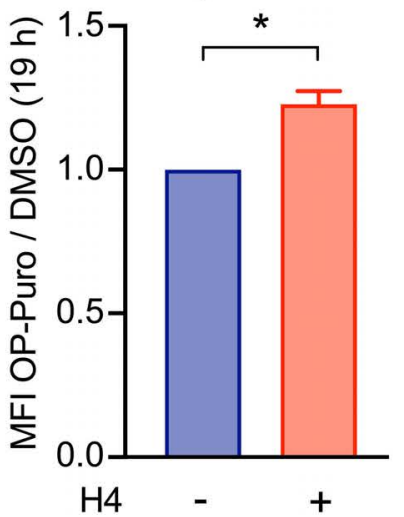

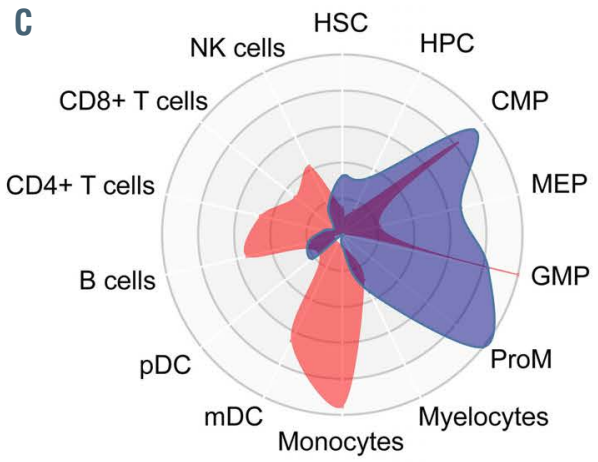

$E$ HALLMARK MYC TARGETS V2

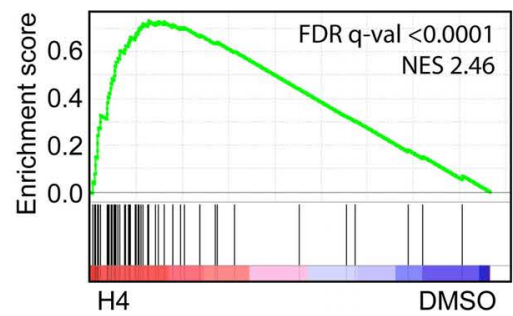

HALLMARK

INTERFERON ALPHA RESPONSE

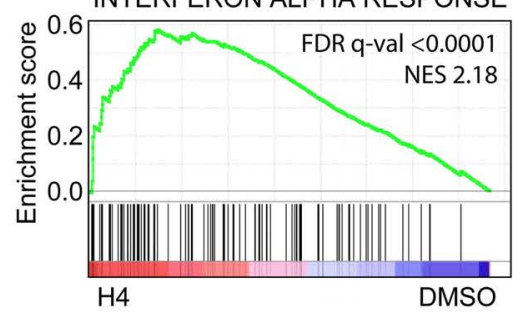

HALLMARK

TNF SIGNALING VIA NFKB

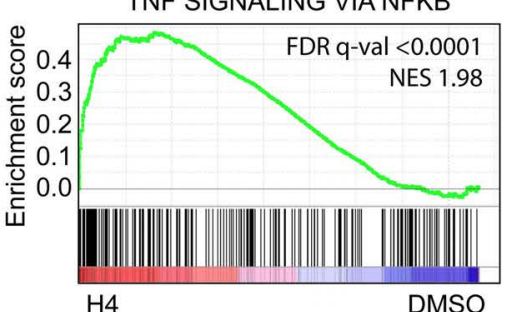

Figure 3. H4 treatment activates the gene expression program of monocytic differentiation. (A) Gene set expression analysis (GSEA) of AML-3 cells after 16 h of treatment with $\mathrm{H} 410 \mu \mathrm{M}$. (B) The 100 most upregulated genes in red and the 100 most downregulated genes in blue after treatment with $\mathrm{H} 4$ compared to dimethylsulfoxide. (C) $\mathrm{H} 4$ treatment triggered a gene expression program of monocytic differentiation with the 100 most upregulated genes associated with monocytic lineage in red and the 100 most downregulated genes associated with myeloid progenitors in blue. Visualized using CellRadar software (developed by G. Karlsson's Laboratory, Lund University; unpublished data from Dhapola et al.) based on gene expression data from normal human hematopoiesis (HemaExplorer) found at the BloodSpot database. ${ }^{24}$ (D) $\mathrm{H} 4$ treatment led to changes in gene expression associated with MYC targets, inflammatory response, and reactive oxygen species pathway. (E) The three most significant Hallmark GSEA plots after treatment with H4. (F) H4 10 uM triggered the upregulation of the monocytic CD64 marker in AML-3 cells after 4 days of treatment. The data shown are mean \pm standard error of mean (SEM) from three independent experiments designated with individual symbols in the lower graph ( ${ }^{*} P<0.05$, ns not significant, using an unpaired two-tailed $t$-test). (G) The translation rate was increased by $\mathrm{H} 410 \mu \mathrm{M}$ treatment of AML-3 cells (measured at $19 \mathrm{~h}$ of treatment). The data are shown as mean \pm SEM of two independent experiments (*P<0.05, using an unpaired two-tailed $t$-test). HSC: hematopoietic stem cells; HPC: hematopoietic progenitor cells; CMP: common myeloid progenitors; MEP: megakaryocyte-erythroid progenitors; GMP: granulocytemacrophage progenitors; ProM: promyelocytes; mDC: myeloid dendritic cells; pDC: plasmacytoid dendritic cells; NK: natural killer; NES: normalized enrichment score; FDR: false discovery rate; DMSO: dimethylsulfoxide; MFI: mean fluorescent intensity. 
euthanized because of the development of AML, while only two out of five mice transplanted with $\mathrm{H} 4$-treated cells had leukemic cells, at barely detectable levels of engraftment $(>0.02 \%$ engraftment in spleen and bone marrow) (Figure 2F and Online Supplementary Figure S2C). These results demonstrate that $\mathrm{H} 4$ can induce differentiation of primary leukemia-propagating cells.

To further investigate the leukemia-differentiating potential of $\mathrm{H} 4$, we next assessed the response of an additional 17 (20 in total) primary samples and seven AML cell lines. Four of the 20 primary samples and two of the cell lines responded with increased CD11b expression (> 20\% increase) (Figure 2G, Table 1, Online Supplementary Table S1, Online Supplementary Figure S3A, B), still without any major toxicity recorded for the tested samples (Table 1, Online Supplementary Figures S2D and S3B). For healthy control cells (CD34 bone marrow cells, CD $34^{+}$peripheral mononuclear cells and peripheral mononuclear cells), only a small increase in CD11b was detected, without altered cell morphology, size, or granularity (Figure 2G, Table 1, Online Supplementary Figure S2E-F). Next, to establish a link between drug response and genetic aberrations, the samples were grouped based on their FLT3 status, which revealed a significant correlation to drug response in primary samples lacking FLT3 mutations (Figure 2G), with a similar trend in AML cell lines (Online Supplementary Figure S3C). These data suggest that the FLT3-ITD/FLT3 mutations confer resistance to the effect of $\mathrm{H} 4$ and that the therapeutic potential is effective in patients with normal FLT3 alleles. In addition, two of the four responding primary samples (with $>20 \%$ increase in CD11b) and the three strongest responding AML cell lines (Figure 2G, Table 1 and Online Supplementary Figure S3A, B), were diagnosed as acute monocytic leukemia (AML subtype M5 according to the French-American-British [FAB] classification) suggesting a favorable drug response for AML blocked at the monoblastic stage. Taken together, we identified $\mathrm{H} 4$ as a differentiating agent of FLT3 wild-type AML.

\section{H4 treatment activates the gene expression program of monocytic differentiation}

To further characterize $\mathrm{H} 4$-induced leukemic differentiation, we performed global gene expression profiling on primary AML-3 cells $16 \mathrm{~h}$ after treatment (Figure 3A). The genes most significantly modulated (42 unique ID, adjusted $P$-value $\left.-\log _{i}>1\right)$ were mainly upregulated, indicating that $\mathrm{H} 4$ treatment leads to transcriptional activation rather than repression (Figure 3B). Next, by comparison of the genes with the greatest fold change in expression to those in a dataset of normal human hematopoiesis ${ }^{24}$ (using CellRadar, developed by G. Karlsson's laboratory at Lund University; unpublished data from Dhapola et al.) we found that the upregulated genes were associated with monocyte maturation and downregulated genes with myeloid progenitor cell identity (Figure 3B, C), supporting that $\mathrm{H} 4$ induces leukemic differentiation towards monocytes. In line with this, gene set enrichment analysis (GSEA) also showed strong enrichment for processes involved in monocytic differentiation and $\mathrm{M} 1$ polarization such as interferon- $\alpha / \gamma$, tumor necrosis factor- $\alpha$ signaling via NF- $\mathrm{kB}$, and reactive oxygen species (Figure 3D, E). ${ }^{14,25}$ In addition, among the upregulated genes, we identified FcyRI (CD64), which is known to be specifically expressed by monocytes and macrophages. ${ }^{26}$ The upregulation was confirmed at the protein level, with there being a 4-fold change in CD64 protein levels 4 days after treatment in comparison to the level in control experiments with DMSO (Figure 3F). Furthermore, gene ontology analysis of the upregulated genes demonstrated significant enrichment of genes coding for ribosomal biogenesis and translational elongation (Online Supplementary Table S2). In line with this, AML-3 cells treated for $19 \mathrm{~h}$ with $\mathrm{H} 4$ showed increased incorporation of OP-Puro, indicating an increased rate of protein translation (Figure 3G). Collectively, these findings demonstrate that $\mathrm{H} 4$ can alter the leukemic molecular program of primary AML to induce leukemic differentiation towards the monocytic lineage.

\section{H4 induces leukemic differentiation through activation of protein kinase $\mathbf{C}$}

To identify candidate signaling pathways enabling H4driven leukemic differentiation, we screened cells from patient AML-3 with $\mathrm{H} 4$ (at $10 \mu \mathrm{M})$ in combination with 176 compounds (Selleck Chem L3000) with defined targets (tested at $0.05 \mu \mathrm{M}, 0.5 \mu \mathrm{M}$, and $10.0 \mu \mathrm{M}$ ) (Figure 4A) Several molecules had an inhibitory effect on H4-dependent CD11b upregulation, with an enrichment of compounds targeting the RAF/MEK/ERK signaling pathway together with JNK and glutaminase 1 (GLS1), all of which are downstream of PKC (Figure 4B and Online Supplementary Figure $S 4 A, B{ }^{27,28}$ In line with this, the addition of the specific PKC inhibitor GF109203X'29 prevented $\mathrm{CD} 11 \mathrm{~b}$ upregulation and the morphological changes of H4-treated AML-3 cells (Figure 4C and Online Supplementary Figure S4C), as well as in the AML cell lines THP-1 and MM6 (Online Supplementary Figure S5A). H4 treatment of 293T cells transfected with PKC-EGFP fusion protein led to a rapid translocation (within $3 \mathrm{~min}$ ) from the cytoplasm to the plasma membrane indicative of direct activation of both conventional PKC $\alpha$ and $\beta$, as well as novel $\varepsilon$ and $\delta$ isoforms ${ }^{30}$ (Figure $4 \mathrm{D}, \mathrm{E}$ and Online Supplementary Video S1-4). Additionally, H4 treatment of FLT3-wild type primary AML-3 cells and the FLT3-ITD AML cell line MOLM-13 led to increased endogenous phospho-PKC activation of both novel and conventional isoforms 30 min after H4 treatment (Figure 4F). Notably, the PKC inhibitor efficiently prevented $\mathrm{CD} 11 \mathrm{~b}$ upregulation by H4 in the FLT3-mutated AML cell line MM6, while the inhibitors of ERK and MEK only had limited effects on H4-induced differentiation. This is in contrast to AML-3 and THP1 where the inhibitors of ERK and MEK efficiently prevented H4-induced differentiation (Online Supplementary Figure S5). Furthermore, the FLT3 inhibitor quizartinib reduced the $\mathrm{H} 4$-induced differentiation in both FLT3 wild-type AML-3 cells and THP1 cells while quizartinib was toxic to the FLT3-mutated MM6 cell line as expected (Figure 4B and Online Supplementary Figure S5). These data support the concept that, mechanistically, H4 relies on activating PKC to promote leukemic differentiation while downstream signaling may be affected differently depending on inter-sample differences. Furthermore, these data underline the robustness of our model as a high throughput platform for mechanistic studies on primary cells.

\section{Combinatorial screening identified a BET inhibitor as an enhancer of H4-induced differentiation}

To identify molecules and pathways that can synergize with $\mathrm{H} 4$, we analyzed the above combinatorial screen for compounds that enhanced H4-driven CD11b upregulation of primary AML-3 cells (Figure 5A). Among the top candi- 
A

AML-3 on

OP9M2 stroma

( 2 days pre-culture)

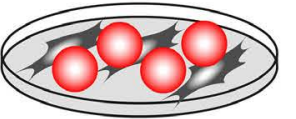

$\mathrm{H} 4+176$ cancer drugs with defined targets

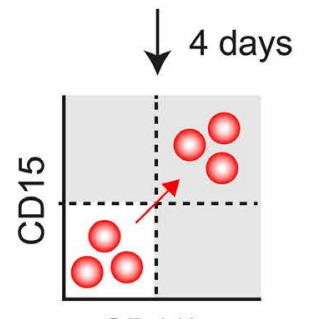

CD11b

C PKC inhibition (AML-3)
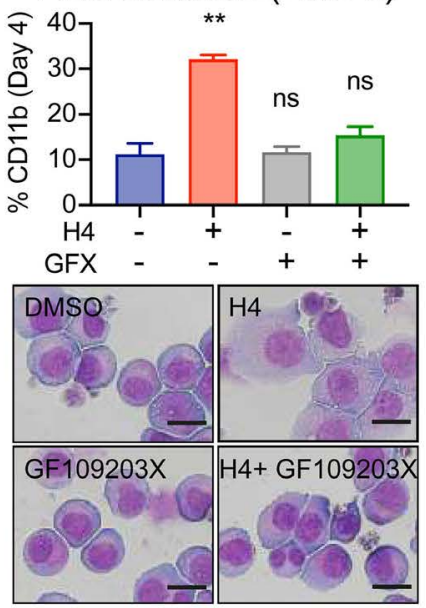

D Confocal live imaging of PKC-GFP translocation

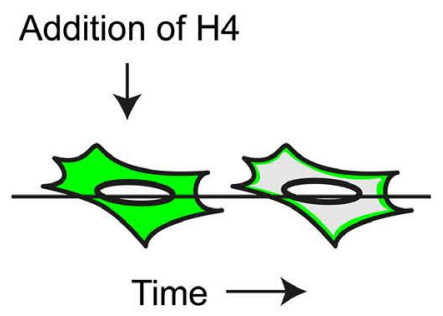

Kinases that inhibit $\mathrm{H} 4$ induced differentiation (AML-3)

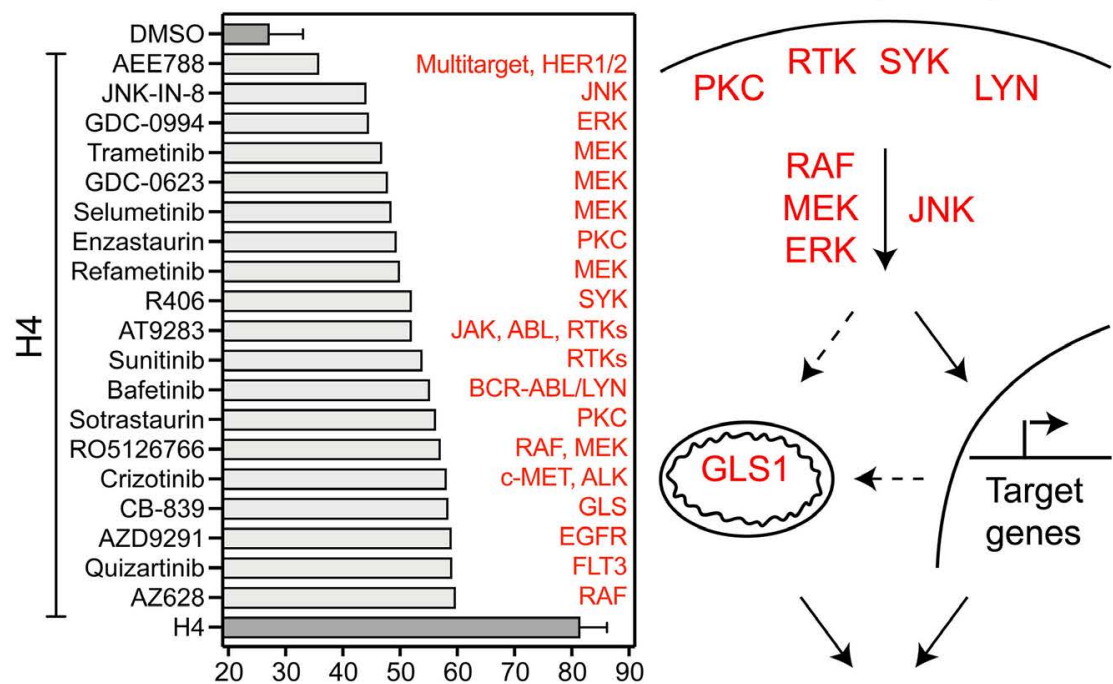

Differentiation
E

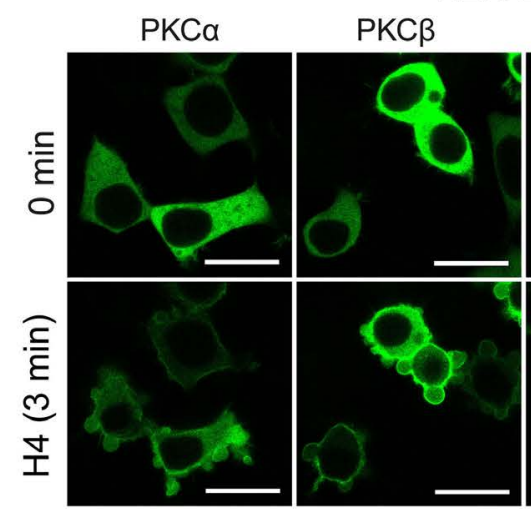

$\mathbf{F}$
$\mathrm{PKC \varepsilon}$

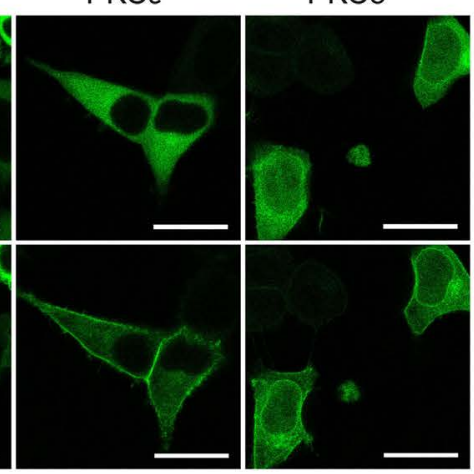

MOLM-13 (FLT3-ITD)

Phosphorylated Phosphorylated Phosphorylated Phosphorylated

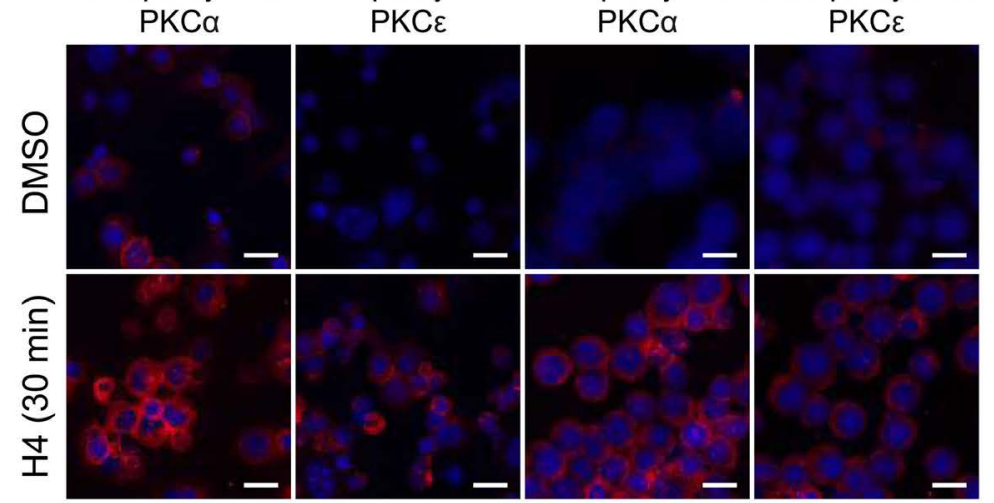

Figure 4. H4 induces leukemic differentiation through activation of PKC. (A) Primary AML-3 cells were treated with 176 compounds $(5 \mu \mathrm{M}, 0.5 \mu \mathrm{M}$, and $0.05 \mu \mathrm{M})$ with defined targets alone and in combination with compound $\mathrm{H} 4(10 \mu \mathrm{M})$. (B) Inhibition of the RAF/MEK/ERK and JNK signaling pathway inhibited H4-induced differentiation together with inhibition of kinases upstream (PKC, RTK, SYK, and LYN) and downstream of the pathway (GLS1). Compounds were omitted from the analysis if their toxicity reduced cell numbers more than $75 \%$ relative to the number following treatment with $\mathrm{H} 4$. The data are shown as mean \pm standard deviation of technical replicates. The schematic diagram on the right shows kinase targets of the most potent compounds and how they relate to each other in signaling pathways. (C) Inhibition of PKC (GF109203X $4 \mu \mathrm{M})$ confirmed that compound H4 (10 $\mu \mathrm{M})$ was unable to differentiate AML-3 cells without intact PKC signaling. Representative examples of MayGrünwald Giemsa staining are shown (scale bars represents $10 \mu \mathrm{m}$ ) and the data are mean \pm standard error of mean from two independent experiments $(* * P<0.01$ ns not significant, using one-way analysis of variance). (D) Schematic illustration of the PKC translocation assay, which is an essential step in PKC activation. HEK-293T cells were transfected with GFP-tagged PKC $\alpha, \beta \mathrm{II}, \varepsilon$, and $\delta$, and treated with $40 \mu \mathrm{M}$ of $\mathrm{H} 4$ for 20 min. Confocal images were taken every $5 \mathrm{~s}$. (E) $\mathrm{H} 4$ triggers the translocation of PKC from the cytosol to membranes. Representative examples of confocal images at 0 and 3 min are shown. Scale bars represent 20 um. (F) $\mathrm{H} 4$ triggers phosphorylaton of PKC $\alpha$ and PKCE in primary AML-3 cells and the AML cell line MOLM-13. Representative examples of confocal images at 30 min of treatment are shown (MOLM-13 PKC $\alpha 40 \mu \mathrm{M}$ of H4 and the rest with $10 \mu \mathrm{M}$ ). Scale bars represent $40 \mu \mathrm{m}$. PKC: protein kinase C; AML: acute myeloid leukemia. 
dates were histone deacetylase inhibitors as well as CPI203 (Figure 5B and Online Supplementary Figure S6), a wellknown BET inhibitor of BRD4. ${ }^{31}$ Notably, while displaying little to no differentiating effect on its own, CPI-203 enhanced the H4-driven increase of CD11b expression, but more strikingly led to a 22 -fold increase of the $\mathrm{CD} 11 \mathrm{~b}$ protein intensity compared to 6-fold with $\mathrm{H} 4$ alone (Figure 5C, Online Supplementary Figure S7, Online Supplementary Table S3). In additional primary samples, the combination enhanced the differentiating effect of $\mathrm{H} 4$ on two out of two FLT3 wild-type AML-M5 samples and in one out of three FLT3-mutated AML-M5 primary samples (Figure 5D, Online Supplementary Figure S7 and Online Supplementary Table S3). The AML-M5 cell lines followed the same pattern, with THP1 (FLT3 wild-type) showing a clear response while MM6 and MOLM-13 (FLT3 mutated) did not respond to the addition of CPI-203 (Online Supplementary
Figures S7 and S8, Online Supplementary Table S3). Finally, the combination of $\mathrm{H} 4$ and the BET inhibitor had no additional effect on the other primary samples regardless of FAB-type or of FLT3 mutation status, except the cell line HL60 (FLT3 wild-type) which responded to the combination (Figure 5D, Online Supplementary Figure S8 and Online Supplementary Table S3). The healthy control also responded to the combination with an increase of $\mathrm{CD} 11 \mathrm{~b}^{+}$cells. However, the increase was still below the $20 \%$ threshold, and no morphological changes were detected (Figure 5D, E, Online Supplementary Figure S7 and Online Supplementary Table S3). Taken together, our findings indicate that among the H4-sensitive primary samples, the combination with the BET inhibitor predominantly affects monocytic (M5) AML.

GSEA of upregulated genes in H4-treated AML-3 cells revealed strong enrichment of MYC target genes (Figure
A

AML-3 on OP9M2 stroma

(2 days pre-culture)

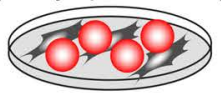

H4 + 176 cancer

drugs with defined drug targets

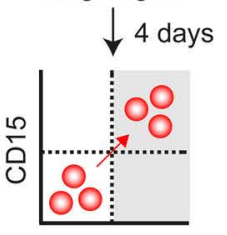

CD11b
B

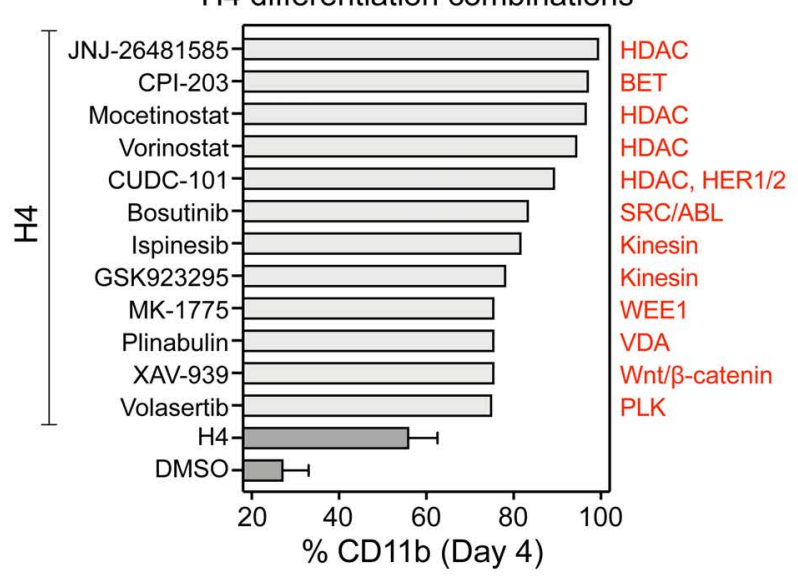

C

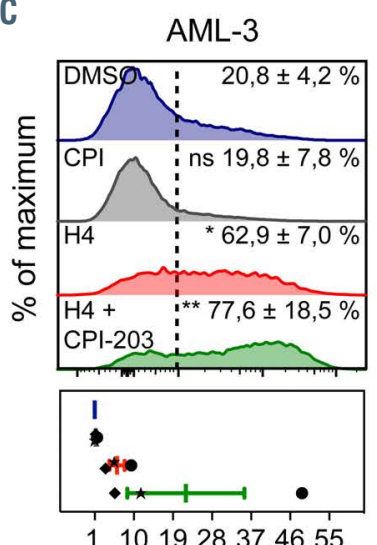

1101928374655 Fold MFI CD11b (Day 4)
D

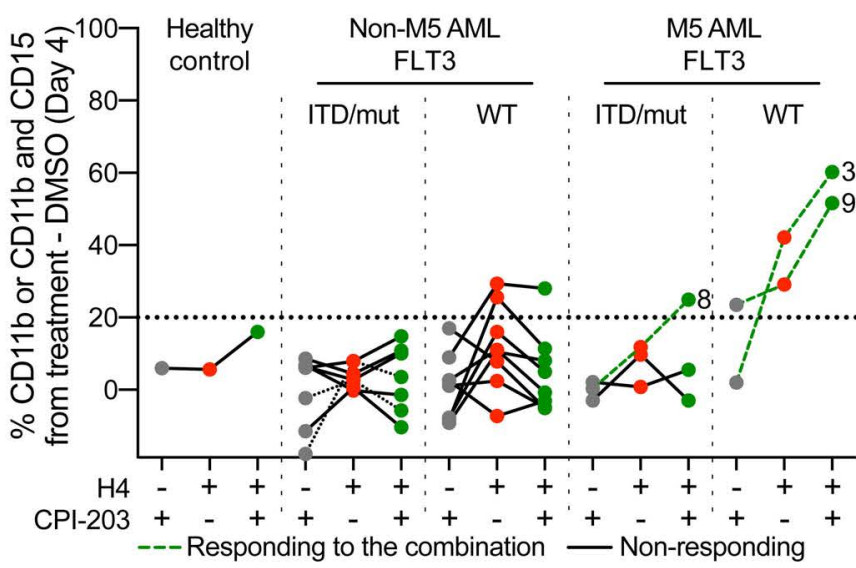

E

Healthy control

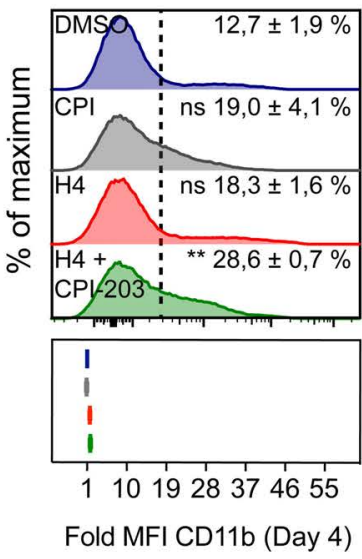

$\mathrm{F}$

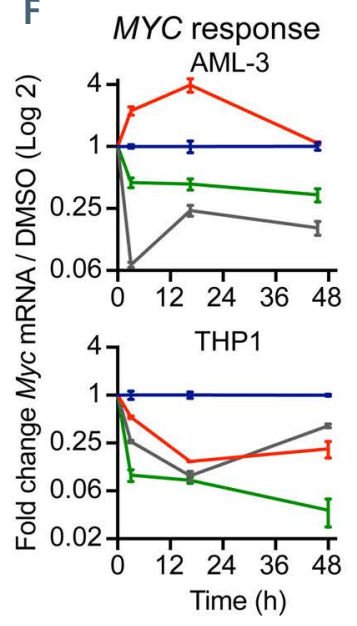

Figure 5. Combinatorial screen identified a BET inhibitor as an enhancer of H4-induced differentiation. (A) Cells from primary AML-3 were treated with 176 compounds $(5 \mu \mathrm{M}, 0.5 \mu \mathrm{M}$, and $0.05 \mu \mathrm{M})$ with defined targets alone and in combination with compound $\mathrm{H} 4(10 \mu \mathrm{M})$. After 4 days, the combinatorial differentiation response was assayed by increased expression of $\mathrm{CD} 11 \mathrm{~b}$ using flow cytometry. (B) The most potent compounds in combination with $\mathrm{H} 4$ are shown in the concentration that did not reduce cell number more than $75 \%$ relative to treatment with $\mathrm{H} 4$ alone (the data are shown as mean \pm standard deviation [SD] of technical replicates). (C) Representative histogram plots showing the combinatorial differentiation effect of $\mathrm{H} 4(10 \mu \mathrm{M})$ and $\mathrm{CPI}-203$ (0.05 $\mu \mathrm{M})$ in AML-3 cells. Lower graphs show fold-change of mean fluorescent intensity (MFI) of CD11b relative to dimethylsulfoxide (DMSO). The data are shown as mean \pm standard error of mean (SEM) from independent experiments designated with individual symbols. ( $* P<0.05, * * P<0.01$, ns not significant, using one-way analysis of variance [ANOVA]). (D) Combining $\mathrm{H} 4(10 \mu \mathrm{M})$ and the BET inhibitor CPI-203 $(0.05 \mu \mathrm{M})$ enhanced differentiation in two out of two FLT3 wild-type and one out of three FLT3-ITD/mutated monocytic AML-M5 samples, while none of 15 samples of other M-types responded to the combination. The healthy control was CD34 ${ }^{+}$umbilical cord blood. Responders (green dashed line) to the combination had to exceed the $20 \%$ cutoff (dotted line) in increased CD11b expression to be categorized as responding. (E) As in panel (C). Healthy control (CD34 ${ }^{+}$umbilical cord blood) $n=3$. ( $* * P<0.01$, ns not significant, using one-way ANOVA). (F) MYC was dispensable for the differentiation response in primary-monocytic AML-3 cells and the monocytic THP1 cell line. Cells were treated with H4 $10 \mu \mathrm{M}$ and CPI-203 $0.05 \mu \mathrm{M}$ alone and in combination. MYC levels are displayed as fold-change compared to DMSO for each time-point. The data are shown as mean \pm SD of technical replicates.DMSO: dimethylsulfoxide; ITD: internal tandem duplication; mut: mutated; WT: wild-type: MFI: mean fluorescent intensity. 
3D, E). As BET inhibitors, such as CPI-203, are known to downregulate $M Y C$ expression, ${ }^{32}$ we next investigated the role of $M Y C$ in H4-dependent differentiation of primary AML-3 cells. While MYC expression increased upon the addition of $\mathrm{H} 4$, treatment with CPI-203 alone or in combination efficiently downregulated $M Y C$ (Figure 5F), indicating that upregulation of $M Y C$ is dispensable in $\mathrm{H} 4$-induced differentiation of AML-3 cells. Notably, the M5 FLT3 wildtype leukemic cell line THP1 responded with MYC downregulation upon $\mathrm{H} 4$ treatment, while the combination with CPI-203 further suppressed MYC expression (Figure 5F). These results suggest that the effect of $\mathrm{H} 4$ can be enhanced with the BET inhibitor CPI-203 in a MYC-independent process. We also provide supporting evidence that the monoblastic nature of AML is a potential prognostic marker of drug sensitivity to H4 and CPI-203. Overall, our study highlights the power and robustness of multiplexed screening on individual primary samples and demonstrates that mutation agnostic combined pathway-targeting can lead to efficient leukemic differentiation.

\section{Discussion}

The 10-year survival of patients with AML between 55 and 64 years is as low as $20 \% .^{2}$ These patients often develop co-morbidities, and their treatment must be chosen with care and often terminated in advance. Therefore, new and more AML-specific treatments with fewer side effects are greatly needed. However, due to the underlying diversity in the regulation of AML, the "one size fits all" strategy will be challenging to pursue, and the key to success is to identify subpopulations of patients with similar responses to selective treatments. Thus, better ways to develop patient-specific treatments with good translation from research to the clinic are needed. In this study, we performed a screen of the effects of natural products on primary AML cells using a co-culture system that simulates the microenvironment in the bone marrow. The screen identified a novel natural compound, called $\mathrm{H} 4$, which induced differentiation of FLT3 wild-type AML. Furthermore, using a combinatorial screen with $\mathrm{H} 4$ and molecules with defined targets, we identified the mechanism of $\mathrm{H} 4$ and determined that PKC activation, together with BET inhibition, further promoted the induction of leukemia differentiation. This demonstrates that our strategy based on a multiplex screening platform can be used for developing combined targeted therapy as well as for gaining mechanistic insights into leukemic regulation.

The novel macrocyclic diterpene identified in this study belongs to the jatrophane class of compounds, previously unknown for its effect on AML. Jatrophanes structurally resemble phorbol molecules known as PKC activators. ${ }^{33}$ In line with this, $\mathrm{H} 4$ activated PKC followed by the downstream MAPK-ERK/JNK pathways that have previously been shown to be crucial to the induction of monocytic differentiation by additional agents such as vitamin D3, iron-chelating drugs, reactive oxygen species-inducing agents, as well as other PKC agonists. ${ }^{34-}$ ${ }^{38}$ Furthermore, the clinical potential of activating this pathway was demonstrated in a retrospective case-control study of AML patients treated with vitamin D3 and an iron-chelating agent which resulted in induced blast cell differentiation and increased overall survival. ${ }^{38,39}$ Hence, further studies are warranted to evaluate $\mathrm{H} 4$ as a clinical candidate, including defining the therapeutic window in vivo.

H4-induced differentiation was found to be dependent on FLT3 status, in that FLT-ITD or FLT3 mutations inhibited the differentiation-inducing capacity of $\mathrm{H} 4$, with the strongest responders being monocytic (M5) FLT3 wildtype leukemias. This indicates that the predicted response is dependent on both the genetic aberrations and in what stage in the hierarchy the differentiation is arrested. The mechanism by which FLT3-ITD or FLT3 mutant signaling inhibits the effect of $\mathrm{H} 4$ is not clear, but since these mutations are often seen as secondary mutations, they may be central in the leukemic transformation and thus directly control the differentiation block. ${ }^{40}$ As such, several essential myeloid transcription factors have been shown to be directly regulated by FLT-ITD such as RUNX1, PU.1 and CEBP/ $\alpha$, which may confer resistance to PKC signling. ${ }^{41,42}$ Since FLT-ITD and FLT3 mutations are among the most common aberrations in AML (being present in around $30 \%$ of all AML patients) ${ }^{7}$ this could limit the use of $\mathrm{H} 4$ clinically. However, in FLT3-ITD or FLT3-mutated AML, it would be interesting to evaluate if H4 combined with FLT3 inhibitors or molecules specifically targeting the downstream effector genes to FLT3 such as $\mathrm{CKI},{ }^{43}$ could unlock the differentiation block, allowing differentiation also in these leukemias.

Gene expression analysis revealed that inflammatory signaling was the primary cellular response to $\mathrm{H} 4$, which, together with the upregulation of CD64, suggests monocytic differentiation towards non-classical inflammatory monocytes by $\mathrm{M} 1$ polarization. ${ }^{44,45}$ We also observed a strong activation of MYC and MYC target genes. Consistent with M1 polarization, MYC is involved in metabolic reprogramming, leading to increased use of glutamine, whose process, when inhibited, also reduced the effect of $\mathrm{H} 4{ }^{46,47}$ However, we and others found that $M Y C$ is downregulated in leukemic cell lines upon PKC activation, ${ }^{35}$ suggesting that the differentiation response in cell lines and primary cells can be mechanistically different. This points to the importance of using individual AML samples for mechanistic studies.

Combinatorial treatment is a strategy to overcome therapy resistance to directed therapy. ${ }^{13,15}$ Nevertheless, identifying combinations based on mutational profile alone is difficult, especially in the context of complex karyotypes. In contrast, using our platform, we could rapidly evaluate hundreds of combinations on primary patients' cells, revealing the combination of CPI-203 (a BET4 inhibitor) and H4. Intriguingly, the combination of PKC agonists with BET inhibitors is an effective strategy to activate latent human immunodeficiency virus (HIV) in CD4 $\mathrm{T}$ cells and monocytes. ${ }^{48}$ Studies on HIV also showed that the combination of BET and PKC enabled optimal efficacy at a lower concentration than using the individual molecules, which is important for reducing potential side effects. In line with this, the optimal concentration for CPI-203 in our study was $50 \mathrm{nM}$, which is non-toxic for healthy bone marrow cells, and below the concentrations used in other studies in which CPI-203 was given alone. ${ }^{49,50}$

Our combination not only improves the effect of $\mathrm{H} 4$ but also potentially improves its clinical potential by removing unwanted side effects such as $M Y C$ expression. Furthermore, it would be interesting to determine whether cancer patients with specific MYC amplifica- 
tions or dysregulated expression of $M Y C$ as part of their tumor mechanism may also benefit, as seen in chronic myeloid leukemia. ${ }^{50}$

In summary, our work highlights the importance of working with primary human samples in mechanistic studies and drug screening. We also show the value of combinatorial treatment to develop novel mutation agnostic therapeutic approaches for AML. Finally, our finding that a combination of PKC activation and BET inhibition promotes increased differentiation in FLT3 wild-type AML provides strong support for further investigation towards clinical use.

\section{Disclosures}

No conflicts of interest to disclose.

\section{Contributions}

SH, $A B, E K$ and $M M$ contributed to the conception and design of the study; $S H, A B$, and $L S$ contributed to the development of the methodology; $S H, A B, P B, R S, F E$ and $M M$ analyzed and interpreted the data; $S H, A B, L S, P B, C S, T F, C L$, $S L, G J, F E$ and $M M$ wrote and reviewed the manuscript; $L S$, $P B, S P-T, C S, T F, R S, C L, S L$ and GJ provided technical or material support; $A B, F E$ and $M M$ supervised the study.

\section{Acknowledgments}

We thank the staff at the Lund Stem Cell FACS Core Facilities for assistance with cell sorting. We also thank Sofia Bengtsson for helping with primary samples and Ben Van Handel for proofreading the manuscript.

\section{Funding}

This work was supported by the Swedish Cancer Foundation, the Swedish Childhood Cancer Foundation, the Swedish Society for Medical Research, the Kamprad Foundation, Gunnar Nilsson and Crafoord.

\section{References}

1. Saultz JN, Garzon R. Acute myeloid leukemia: a concise review. J Clin Med. 2016;5(3):33.

2. Juliusson G, Lazarevic V, Horstedt AS, Hagberg O, Hoglund M, Swedish Acute Leukemia Registry Group. Acute myeloid leukemia in the real world: why populationbased registries are needed. Blood. 2012;119 (17):3890-3899.

3. Pollyea DA, Tallman MS, de Botton S, et al. Enasidenib, an inhibitor of mutant IDH2 proteins, induces durable remissions in older patients with newly diagnosed acute myeloid leukemia. Leukemia. 2019;33(11): 2575-2584.

4. Waitkus MS, Diplas BH, Yan H. Biological role and therapeutic potential of IDH mutations in cancer. Cancer Cell. 2018;34(2):186195.

5. Kalmanti L, Saussele S, Lauseker M, et al. Safety and efficacy of imatinib in CML over a period of 10 years: data from the randomized CML-study IV. Leukemia. 2015;29(5): 1123-1132

6. Lo-Coco F, Di Donato L, GIMEMA; Schlenk RF, German-Austrian Acute Myeloid Leukemia Study Group and Study Alliance Leukemia. Targeted therapy alone for acute promyelocytic leukemia. N Engl J Med. 2016;374(12):1197-1198

7. Daver N, Schlenk RF, Russell NH, Levis MJ. Targeting FLT3 mutations in AML: review of current knowledge and evidence. Leukemia. 2019;33(2):299-312.

8. Coombs CC, Tallman MS, Levine RL. Molecular therapy for acute myeloid leukaemia. Nat Rev Clin Oncol. 2016;13(5): 305-318.

9. Amatangelo MD, Quek L, Shih A, et al. Enasidenib induces acute myeloid leukemia cell differentiation to promote clinical response. Blood. 2017;130(6):732-741.

10. Cortes JE, Khaled S, Martinelli G, et al. Quizartinib versus salvage chemotherapy in relapsed or refractory FLT3-ITD acute myeloid leukaemia (QuANTUM-R): a multicentre, randomised, controlled, open-label, phase 3 trial. Lancet Oncol. 2019;20(7):984997.

11. Quek L, David MD, Kennedy A, et al. Clonal heterogeneity of acute myeloid leukemia treated with the IDH2 inhibitor enasidenib. Nat Med. 2018;24(8):1167-1177.

12. Kasi PM, Litzow MR, Patnaik MM, Hashmi
SK, Gangat N. Clonal evolution of AML on novel FMS-like tyrosine kinase-3 (FLT3) inhibitor therapy with evolving actionable targets. Leuk Res Rep. 2016;5:7-10.

13. Ablain J, Rice K, Soilihi H, de Reynies A, Minucci S, de The $\mathrm{H}$. Activation of a promyelocytic leukemia-tumor protein 53 axis underlies acute promyelocytic leukemia cure. Nat Med. 2014;20(2):167-174.

14. de The H. Differentiation therapy revisited Nat Rev Cancer. 2018;18(2):117-127.

15. Shen ZX, Shi ZZ, Fang J, et al. All-trans retinoic acid/As2O3 combination yields a high quality remission and survival in newly diagnosed acute promyelocytic leukemia. Proc Natl Acad Sci U S A. 2004;101 (15):5328-5335.

16. Cancer Genome Atlas Research N, Ley TJ, Miller C, et al. Genomic and epigenomic landscapes of adult de novo acute myeloid leukemia. N Engl J Med. 2013;368(22):20592074

17. Baudet A, Ek F, Davidsson J, et al. Small molecule screen identifies differentiation-promoting compounds targeting genetically diverse acute myeloid leukaemia. $\mathrm{Br} \mathrm{J}$ Haematol. 2016;175(2):342-346.

18. Griessinger E, Anjos-Afonso F, Pizzitola I, et al. A niche-like culture system allowing the maintenance of primary human acute myeloid leukemia-initiating cells: a new tool to decipher their chemoresistance and selfrenewal mechanisms. Stem Cells Transl Med. 2014;3(4):520-529.

19. Klco JM, Spencer DH, Miller CA, et al. Functional heterogeneity of genetically defined subclones in acute myeloid leukemia. Cancer Cell. 2014;25(3):379-392.

20. Zeidman R, Lofgren B, Pahlman S, Larsson C. PKCepsilon, via its regulatory domain and independently of its catalytic domain, induces neurite-like processes in neuroblastoma cells. J Cell Biol. 1999;145(4):713-726.

21. Magnusson M, Sierra MI, Sasidharan R, et al. Expansion on stromal cells preserves the undifferentiated state of human hematopoietic stem cells despite compromised reconstitution ability. PLoS One. 2013;8(1): e53912.

22. Salehi B, Iriti M, Vitalini S, et al. Euphorbiaderived natural products with potential for use in health maintenance. Biomolecules. 2019;9(8):337.

23. Fry DW, Harvey PJ, Keller PR, et al. Specific inhibition of cyclin-dependent kinase $4 / 6$ by PD 0332991 and associated antitumor activ- ity in human tumor xenografts. Mol Cancer Ther. 2004;3(11):1427-1438.

24. Bagger FO, Kinalis S, Rapin N. BloodSpot: database of healthy and malignant haematopoiesis updated with purified and single cell mRNA sequencing profiles. Nucleic Acids Res. 2019;47(D1):D881-D885

25. Lawrence T, Natoli G. Transcriptional regulation of macrophage polarization: enabling diversity with identity. Nat Rev Immunol. 2011;11(11):750-761.

26. Zhang H, Li L, Liu L. FcgammaRI (CD64) contributes to the severity of immune inflammation through regulating NFkappaB/NLRP3 inflammasome pathway. Life Sci. 2018;207:296-303.

27.Zeke A, Misheva M, Remenyi A, Bogoyevitch MA. JNK signaling: regulation and functions based on complex proteinprotein partnerships. Microbiol Mol Biol Rev. 2016;80(3):793-835.

28. Thangavelu K, Pan CQ, Karlberg T, et al. Structural basis for the allosteric inhibitory mechanism of human kidney-type glutaminase (KGA) and its regulation by Raf-MekErk signaling in cancer cell metabolism. Proc Natl Acad Sci U S A. 2012;109(20):77057710 .

29. Toullec D, Pianetti P, Coste $\mathrm{H}$, et al. The bisindolylmaleimide GF 109203X is a potent and selective inhibitor of protein kinase C. J Biol Chem. 1991;266(24):15771-15781.

30. Mochly-Rosen D, Das K, Grimes KV. Protein kinase C, an elusive therapeutic target? Nat Rev Drug Discov. 2012;11(12):937957.

31. Devaiah BN, Lewis BA, Cherman N, et al. BRD4 is an atypical kinase that phosphorylates serine 2 of the RNA polymerase II carboxy-terminal domain. Proc Natl Acad Sci U S A. 2012;109(18):6927-6932.

32. Wong C, Laddha SV, Tang L, et al. The bromodomain and extra-terminal inhibitor CPI203 enhances the antiproliferative effects of rapamycin on human neuroendocrine tumors. Cell Death Dis. 2014;5(10):e1450.

33. Bedoya LM, Marquez N, Martinez N, et al. $\mathrm{SJ} 23 \mathrm{~B}$, a jatrophane diterpene activates classical PKCs and displays strong activity against HIV in vitro. Biochem Pharmacol. 2009;77(6):965-978.

34. Hughes PJ, Marcinkowska E, Gocek E, Studzinski GP, Brown G. Vitamin D3-driven signals for myeloid cell differentiation-implications for differentiation therapy. Leuk Res. 2010;34(5):553-565 
35. Yu ZY, Xiao H, Wang LM, et al. Natural product vibsanin $\mathrm{A}$ induces differentiation of myeloid leukemia cells through PKC activation. Cancer Res. 2016;76(9):2698-2709.

36. Kharbanda S, Saleem A, Emoto Y, Stone R, Rapp U, Kufe D. Activation of Raf-1 and mitogen-activated protein kinases during monocytic differentiation of human myeloid leukemia cells. J Biol Chem. 1994:269(2):872-878

37. Liu CX, Zhou HC, Yin QQ, Wu YL, Chen GQ. Targeting peroxiredoxins against leukemia. Exp Cell Res. 2013;319(2):170176.

38. Callens C, Coulon S, Naudin J, et al. Targeting iron homeostasis induces cellular differentiation and synergizes with differentiating agents in acute myeloid leukemia. J Exp Med. 2010;207(4):731-750.

39. Paubelle E, Zylbersztejn F, Alkhaeir S, et al. Deferasirox and vitamin D improves overall survival in elderly patients with acute myeloid leukemia after demethylating agents failure. PLoS One. 2013;8(6):e65998.
40. Shlush LI, Zandi S, Mitchell A, et al. Identification of pre-leukaemic haematopoietic stem cells in acute leukaemia. Nature. 2014:506(7488):328-333.

41. Behrens K, Maul K, Tekin N, et al. RUNX1 cooperates with FLT3-ITD to induce leukemia. J Exp Med. 2017;214(3):737-752.

42. Mizuki M, Schwable J, Steur C, et al. Suppression of myeloid transcription factors and induction of STAT response genes by AML-specific Flt3 mutations. Blood. 2003;101(8):3164-3173.

43. Radomska HS, Alberich-Jorda M, Will B Gonzalez D, Delwel R, Tenen DG Targeting CDK1 promotes FLT3-activated acute myeloid leukemia differentiation through C/EBPalpha. J Clin Invest. 2012;122 (8):2955-2966.

44. Italiani P, Boraschi D. From monocytes to M1/M2 macrophages: phenotypical vs. functional differentiation. Front Immunol. 2014;5:514.

45. Hristodorov D, Mladenov R, von Felbert V, et al. Targeting CD64 mediates elimination of $\mathrm{M} 1$ but not $\mathrm{M} 2$ macrophages in vitro and in cutaneous inflammation in mice and patient biopsies. MAbs. 2015;7(5):853-862.

46. O'Neill LA, Hardie DG. Metabolism of inflammation limited by AMPK and pseudostarvation. Nature. 2013;493(7432):346-355.

47. Wang R, Dillon CP, Shi LZ, et al. The transcription factor Myc controls metabolic reprogramming upon $\mathrm{T}$ lymphocyte activation. Immunity. 2011;35(6):871-882 .

48. Shi J, Vakoc CR. The mechanisms behind the therapeutic activity of BET bromodomain inhibition. Mol Cell. 2014;54(5):728-736.

49. Diaz T, Rodriguez V, Lozano E, et al. The BET bromodomain inhibitor CPI203 improves lenalidomide and dexamethasone activity in in vitro and in vivo models of multiple myeloma by blockade of Ikaros and MYC signaling. Haematologica. 2017;102(10): 1776-1784

50. Abraham SA, Hopcroft LE, Carrick E, et al. Dual targeting of $\mathrm{p} 53$ and c-MYC selectively eliminates leukaemic stem cells. Nature. 2016;534(7607):341-346. 